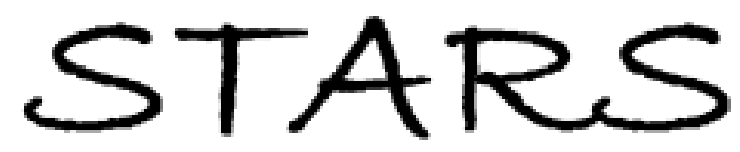

University of Central Florida

STARS

$1-1-2010$

\title{
Temperature dependence of binary and ternary recombination of D-3(+) ions with electrons
}

\author{
T. Kotrík \\ P. Dohnal \\ I. Korolov \\ R. Plašil \\ Š. Roučka
}

See next page for additional authors

Find similar works at: https://stars.library.ucf.edu/facultybib2010

University of Central Florida Libraries http://library.ucf.edu

This Article is brought to you for free and open access by the Faculty Bibliography at STARS. It has been accepted for inclusion in Faculty Bibliography 2010 s by an authorized administrator of STARS. For more information, please contactSTARS@ucf.edu.

\section{Recommended Citation}

Kotrík, T.; Dohnal, P.; Korolov, I.; Plašil, R.; Roučka, Š.; Glosík, J.; Greene, Chris H.; and Kokoouline, V., "Temperature dependence of binary and ternary recombination of D-3(+) ions with electrons" (2010). Faculty Bibliography 2010s. 381.

https://stars.library.ucf.edu/facultybib2010/381

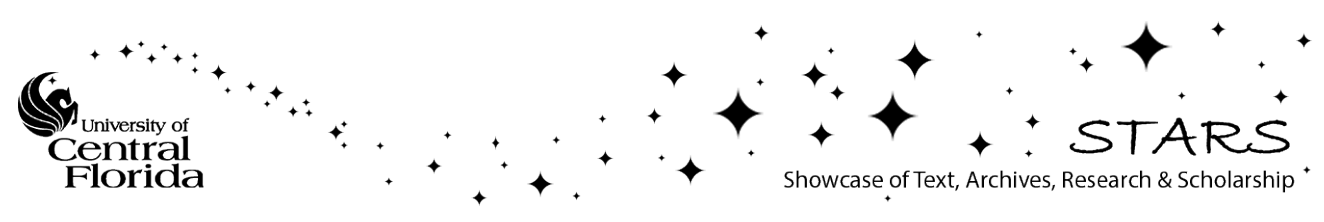


Authors

T. Kotrík, P. Dohnal, I. Korolov, R. Plašil, Š. Roučka, J. Glosík, Chris H. Greene, and V. Kokoouline 


\section{Temperature dependence of binary and ternary recombination of $\mathrm{D}_{3}^{+}$ions with electrons}

Cite as: J. Chem. Phys. 133, 034305 (2010); https://doi.org/10.1063/1.3457940

Submitted: 06 April 2010 . Accepted: 08 June 2010 . Published Online: 21 July 2010

T. Kotrík, P. Dohnal, I. Korolov, R. Plašil, Š. Roučka, J. Glosík, Chris H. Greene, and V. Kokoouline

\section{ARTICLES YOU MAY BE INTERESTED IN}

Flowing-afterglow study of electron-ion recombination of para- $\mathrm{H}_{3}^{+}$and ortho- $\mathrm{H}_{3}^{+}$ions at temperatures from $60 \mathrm{~K}$ to $300 \mathrm{~K}$

The Journal of Chemical Physics 143, 044303 (2015); https://doi.org/10.1063/1.4927094

Binary and ternary recombination of $D_{3}^{+}$ions at $80-130 \mathrm{~K}$ : Application of laser absorption spectroscopy

The Journal of Chemical Physics 137, 194320 (2012); https://doi.org/10.1063/1.4767396

Binary and ternary recombination of para- $H_{3}^{+}$and ortho- $H_{3}^{+}$with electrons: State selective study at 77-200 K

The Journal of Chemical Physics 136, 244304 (2012); https://doi.org/10.1063/1.4730162

Where in the world is AIP Publishing? Find out where we are exhibiting next 


\title{
Temperature dependence of binary and ternary recombination of $D_{3}^{+}$ions with electrons
}

\author{
T. Kotrík, ${ }^{1}$ P. Dohnal, ${ }^{1}$ I. Korolov, ${ }^{1}$ R. Plašill, ${ }^{1, a)}$ Š. Roučka, ${ }^{1}$ J. Glosík, ${ }^{1}$ Chris H. Greene,${ }^{2}$ \\ and V. Kokoouline ${ }^{3,4}$ \\ ${ }^{1}$ Faculty of Mathematics and Physics, Charles University, 12116 Prague, Czech Republic \\ ${ }^{2}$ Department of Physics and JILA, University of Colorado, Boulder, Colorado 80309-0440, USA \\ ${ }^{3}$ Department of Physics, University of Central Florida, Orlando, Florida 32816, USA \\ ${ }^{4}$ Laboratoire Aimé Cotton, CNRS, Université Paris-Sud XI, 91405 Orsay, France
}

(Received 6 April 2010; accepted 8 June 2010; published online 21 July 2010)

\begin{abstract}
Flowing and stationary afterglow experiments were performed to study the recombination of $\mathrm{D}_{3}^{+}$ ions with electrons at temperatures from 77 to $300 \mathrm{~K}$. A linear dependence of apparent (effective) binary recombination rate coefficients on the pressure of the helium buffer gas was observed. Binary $\left(\mathrm{D}_{3}^{+}+e^{-}\right)$and ternary $\left(\mathrm{D}_{3}^{+}+e^{-}+\mathrm{He}\right)$ recombination rate coefficients were derived. The obtained binary rate coefficient agrees with recent theoretical values for dissociative recombination of $\mathrm{D}_{3}^{+}$. We describe the observed ternary process by a mechanism with two rate determining steps. In the first step, a rotationally excited long-lived neutral $\mathrm{D}_{3}^{*}$ is formed in $\mathrm{D}_{3}^{+}-e^{-}$collisions. As the second step, the $\mathrm{D}_{3}^{*}$ collides with a helium atom that prevents autoionization of $\mathrm{D}_{3}^{*}$. We calculate lifetimes of $\mathrm{D}_{3}^{*}$ formed from ortho-, para-, or metastates of $\mathrm{D}_{3}^{+}$and use the lifetimes to calculate ternary recombination rate coefficients. (C) 2010 American Institute of Physics. [doi:10.1063/1.3457940]
\end{abstract}

\section{INTRODUCTION}

Since the 1950s the recombination of $\mathrm{H}_{3}^{+}$ions with electrons has been considered one of the most important problems in recombination studies because of its fundamental importance for plasma physics, theoretical atomic physics, and astrophysics. ${ }^{1-10}$ The problem of $\mathrm{H}_{3}^{+}$recombination motivated many theoretical and experimental studies when the infrared absorption spectrum of $\mathrm{H}_{3}^{+}$was observed ${ }^{11}$ and $\mathrm{H}_{3}^{+}$ was discovered in the auroral regions of Jupiter ${ }^{12}$ and in the interstellar space. $^{13,14}$

Before the year 2001, no theoretical explanation existed for the relatively fast rate of recombination of $\mathrm{H}_{3}^{+}$with electrons that was observed in most experiments with $\mathrm{H}_{3}^{+} .{ }^{15-19} \mathrm{In}$ addition, there was a significant difference in recombination rate coefficients obtained in different experiments. ${ }^{17,20}$ The spectroscopic experiments with $\mathrm{H}_{3}^{+}$did not solve the problem. ${ }^{21-24} \mathrm{Up}$ to now, the spectroscopic study of $\mathrm{D}_{3}^{+}$recombination has not been reported at all.

The understanding of the main mechanism of binary dissociative recombination (DR) of $\mathrm{H}_{3}^{+}$and $\mathrm{D}_{3}^{+}$improved when the Jahn-Teller coupling was included in the theory. ${ }^{25-28}$ For a plasma in thermodynamic equilibrium the obtained theoretical values of the binary rate coefficients of the $\mathrm{DR}$ of $\mathrm{H}_{3}^{+}$and $\mathrm{D}_{3}^{+}$ions are $\alpha_{\mathrm{H}_{3}^{+}}(300 \mathrm{~K})=5.6 \times 10^{-8} \mathrm{~cm}^{3} \mathrm{~s}^{-1}$ and $\alpha_{\mathrm{D}_{3}^{+}}(300 \mathrm{~K})=4 \times 10^{-8} \mathrm{~cm}^{3} \mathrm{~s}^{-1}$, respectively. ${ }^{29,30}$ The theory of DR predicted for $\mathrm{H}_{3}^{+}$(and isotopologues) 26,27,31,32 that the cross-sections depend on the rotational excitation of the ions. In addition, it was shown ${ }^{27,32-34}$ that electron-ion collisions can cause rotational excitation and de-excitation of the ion with a high probability. In recent storage-ring experiments with cold $\mathrm{H}_{3}^{+}$ion sources the recombination rate coefficients

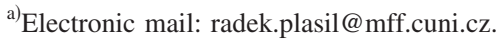

obtained agree well with the theoretical predictions. ${ }^{35,36}$ In the Heidelberg TSR experiment, ${ }^{37}$ the DR cross-section obtained for paraenriched $\mathrm{H}_{3}^{+}$at low collision energies was found to be larger than the cross-section for "normal" ortho-/ paramixture. These results have been confirmed in recent CRYRING experiments in Stockholm. ${ }^{38}$ We have to mention here that there is no direct (in situ) determination of the state population of recombining ions in the storage rings. Up to now, no storage-ring measurement with cold and state selected $\mathrm{D}_{3}^{+}$has been carried out.

We have studied the recombination of both $\mathrm{H}_{3}^{+}$and $\mathrm{D}_{3}^{+}$ ions with electrons in several plasma experiments: Advanced Integrated Stationary Afterglow (AISA) (Refs. 6, 7, 39, and 40) and several modifications of the Flowing Afterglow with Langmuir Probe (FALP). ${ }^{41-43}$ It was found that the measured recombination rate coefficients depend on the $\mathrm{H}_{2}$ (and $\mathrm{D}_{2}$ ) densities. ${ }^{6,7,39-43}$ By measuring the He-pressure dependence, we came to the conclusion that, in conditions typical for afterglow experiments (77-300 K and 100-2000 Pa), the recombination of $\mathrm{H}_{3}^{+}$and $\mathrm{D}_{3}^{+}$ions with electrons is not a pure binary process, ${ }^{44-46}$ helium and molecular hydrogen participate as the third body in $\mathrm{H}_{3}^{+}+e^{-}$and $\mathrm{D}_{3}^{+}+e^{-}$recombination.

The main focus of the present paper is the recombination process in a $\mathrm{D}_{3}^{+}$-dominated afterglow plasma. The observed plasma "deionization" can be described by an apparent (effective) binary recombination rate coefficient, $\alpha_{\text {eff }}=\alpha_{\text {eff }}\left(T,\left[\mathrm{D}_{2}\right],[\mathrm{He}]\right){ }^{44-46}$ The index "eff" stresses the fact that we measure the "effective binary recombination rate coefficient" from the rate of plasma deionization. The measured dependence of $\alpha_{\text {eff }}$ on $\left[\mathrm{D}_{2}\right]$ and [He] suggests that the observed deionization process may involve several parallel and competing channels.

The sequence of collisions leading to recombination can start with $\left(\mathrm{D}_{3}^{+}+\mathrm{D}_{2}\right),\left(\mathrm{D}_{3}^{+}+\mathrm{He}\right)$, or $\left(\mathrm{D}_{3}^{+}+e^{-}\right)$collision. Colli- 
sions and $\left(\mathrm{D}_{3}^{+}+e^{-}\right)$are discussed in detail below. The $\left(D_{3}^{+}+D_{2}\right)$ collisions can lead to the formation of the intermediate van der Waals molecular ion $\mathrm{D}_{3}^{+} \cdot \mathrm{D}_{2}$ which can be stabilized in a low temperature plasma (the process known as ternary association, see, e.g., Ref. 43, 47, and 48). After the $\mathrm{D}_{5}^{+}$ion is formed, the process of "deionization" is terminated by a fast dissociative recombination between $\mathrm{D}_{5}^{+}$and $e^{-}$. The process has been discussed quantitatively in previous studies. ${ }^{41,43,48-50}$ Formation of $\mathrm{D}_{3}^{+} \cdot \mathrm{He}$ is not considered because of its low dissociation energy.

Neutral unstable $\mathrm{D}_{3}$ and $\mathrm{H}_{3}$ molecules have been observed many times in plasmas. ${ }^{51,52}$ The lifetimes of certain electronic states of $\mathrm{D}_{3}$ and $\mathrm{H}_{3}$ molecules were calculated ${ }^{53}$ and measured. ${ }^{54}$ Only certain electronic states of $\mathrm{D}_{3}$ can be populated due to collisions $\mathrm{D}_{3}^{+}+e^{-}$. Our calculations suggest that at low electron energies long-lived highly excited neutral $\mathrm{D}_{3}^{*}$ (molecular Rydberg states) can be formed. This can lead to ternary recombination in plasma. We found experimentally that the recombination of $\mathrm{D}_{3}^{+}$plasma depends also on the helium density at $200-300 \mathrm{~K}^{46}$ In the present study we have extended our measurements down to $77 \mathrm{~K}$.

Ternary electron-ion recombination was predicted by Thomson ${ }^{55}$ and by Bates and Khare ${ }^{56}$ and observed in experiments. ${ }^{57-59}$ The ternary recombination of $\mathrm{D}_{3}^{+}$and $\mathrm{H}_{3}^{+}$ ions observed in our studies can be, depending on the temperature, more effective than their estimate by a factor of 100. It is an essentially different process than the process considered by Thomson. The large rate coefficients of the observed ternary recombination of $\mathrm{D}_{3}^{+}$and $\mathrm{H}_{3}^{+}$are mainly due to the long autoionization lifetimes of highly excited Rydberg molecules formed in collision between $\mathrm{D}_{3}^{+}\left(\right.$or $\mathrm{H}_{3}^{+}$) and electrons at low temperatures.

\section{EXPERIMENTS}

Several modifications of flowing afterglow experiments were used in the presented work (see description in Refs. 43 and 60-62). The Cryo-FALP designed to operate at temperatures in the range $77-300 \mathrm{~K}$ and at helium pressure 200 $2000 \mathrm{~Pa}$ was constructed and used for low temperature studies. In Cryo-FALP, the plasma is created in the upstream glass section of the flow tube (at $300 \mathrm{~K}$ ) in the microwave discharge $(10-30 \mathrm{~W})$ in pure helium. Because of the high pressure, $\mathrm{He}^{+}$ions formed in the discharge react in a threebody association reaction forming a $\mathrm{He}_{2}^{+}$-dominated plasma. Downstream from the discharge, Ar is added and the plasma becomes $\mathrm{Ar}^{+}$dominated (see details of the formation in Refs. 7, 39, and 43).

Metastable $\mathrm{He}$ atoms formed in the discharge are removed from the afterglow by Penning ionization when Ar is added (see Refs. 7 and 63). Via the second entry port (35 ms downstream from the Ar entry port), $\mathrm{D}_{2}$ is introduced into the already relaxed cold plasma. In a sequence of ionmolecule reactions, the $\mathrm{D}_{3}^{+}$dominated plasma is formed. A numerical model is used to simulate the processes along the flow tube. Analysis of the data calculated for $\left[\mathrm{D}_{2}\right]=2.4$ $\times 10^{12} \mathrm{~cm}^{-3}$ reveals that $\mathrm{D}_{3}^{+}$becomes the dominant ion in the decaying plasma approximately $2 \mathrm{~ms}$ after $\mathrm{D}_{2}$ is added. Argon plays a role in plasma relaxation and in the formation of $\mathrm{D}_{3}^{+}$but after the $\mathrm{D}_{3}^{+}$-dominated plasma is formed, Ar does not participate in ion chemistry anymore. Only at very high [Ar], the clusters $\mathrm{D}_{3}^{+}$. Ar can be formed. ${ }^{64}$ In the present experiments we are using low Ar densities so we can neglect the formation of $\mathrm{D}_{3}^{+}$. Ar. Note that formed $\mathrm{D}_{3}^{+}$has several collisions with $\mathrm{D}_{2}$ prior to its recombination so we can expect quenching of eventual internal excitation of $\mathrm{D}_{3}^{+}$ions gained from exothermicity of forming reactions (see also discussion below).

Downstream from the Ar entry port the flow tube is cooled by liquid nitrogen to the required temperature. An axially movable Langmuir probe ${ }^{63,65}$ is used to monitor the electron density decay downstream from the deuterium entry port. This probe was calibrated by the well-known rate coefficient of $\mathrm{O}_{2}^{+}$recombination. ${ }^{5}$ In fact, the calibration just confirmed accuracy of electron density measurements based on probe theory (see also the discussion in Refs. 6, 7, 42, 62, and 65-67).

Although the plasma decay in $\mathrm{D}_{3}^{+}$dominated plasma is governed by several parallel recombination processes, we introduce a single parameter of the decay-the effective apparent binary recombination rate coefficient $\alpha_{\text {eff }}$. The decay can then be described by the balance equation:

$$
\frac{\mathrm{d} n_{\mathrm{e}}}{\mathrm{d} t}=-\alpha_{\mathrm{eff}} n_{\mathrm{i}} n_{\mathrm{e}}-\frac{n_{\mathrm{e}}}{\tau_{\mathrm{D}}}=-\alpha_{\mathrm{eff}} n_{\mathrm{e}}^{2}-\frac{n_{\mathrm{e}}}{\tau_{\mathrm{D}}},
$$

where $n_{\mathrm{e}}$ and $n_{\mathrm{i}}$ are electron and ion densities. We assume that the plasma is quasineutral $\left(n_{\mathrm{e}}=n_{\mathrm{i}}\right)$ and the constant $\tau_{\mathrm{D}}$ characterizes the ambipolar diffusion during the afterglow. In the experiments we used $\mathrm{He}$ and $\mathrm{D}_{2}$ densities in the interval $[\mathrm{He}] \approx 6 \times 10^{16}-6 \times 10^{17} \mathrm{~cm}^{-3}$ and $\left[\mathrm{D}_{2}\right] \approx 10^{11}-10^{15} \mathrm{~cm}^{-3}$. Analyzing dependencies of $\alpha_{\text {eff }}$ on $[\mathrm{He}]$ and $\left[\mathrm{D}_{2}\right]$ and on temperature we have obtained $\alpha_{\text {eff }}=\alpha_{\text {eff }}\left(T,\left[\mathrm{D}_{2}\right],[\mathrm{He}]\right)$.

\section{EXPERIMENTAL RESULTS}

To obtain effective recombination rate coefficients we measured the electron density decay along the flow tube in a $\mathrm{He} / \mathrm{Ar} / \mathrm{D}_{2}$ mixture. A few examples of decay curves, measured in the $\mathrm{D}_{3}^{+}$dominated afterglow plasma at $77 \mathrm{~K}$ and at several $\mathrm{D}_{2}$ densities, are plotted in panel (a) of Fig. 1. The dependence of the decay rate on $\left[\mathrm{D}_{2}\right]$ is evident (see discussion in Refs. 7, 39, and 44-46). Some examples of decay curves measured at higher temperatures are plotted in panel (b) of Fig. 1.

In Fig. 2 the measured effective binary recombination rate coefficients $\left(\alpha_{\text {eff }}\right)$, are plotted as functions of $\left[D_{2}\right]$. We also show the data previously obtained in other experiments. Below we discuss in detail the data plotted in the figure.

Panel (a) of Fig. 2:

(1) $77 \mathrm{~K}$; Cryo-FALP. At a fixed flow tube temperature $T=77 \mathrm{~K}$ and at $[\mathrm{He}]=2.1 \times 10^{17} \mathrm{~cm}^{-3}$ the dependence of $\alpha_{\text {eff }}$ on $\left[\mathrm{D}_{2}\right]$ was measured in the interval $3 \times 10^{11} \mathrm{~cm}^{-3}<\left[\mathrm{D}_{2}\right] \leqslant 4 \times 10^{13} \mathrm{~cm}^{-3}$. For two other helium densities, $\alpha_{\text {eff }}$ was measured only over a limited range, $\left[D_{2}\right] \approx(2-10) \times 10^{12} \mathrm{~cm}^{-3}$. The measured dependencies have a plateau where $\alpha_{\text {eff }}$ is independent on $\left[\mathrm{D}_{2}\right]$. Notice that the data obtained at different $[\mathrm{He}]$ overlap, indicating that at $77 \mathrm{~K}$ the dependence of $\alpha_{\text {eff }}$ 


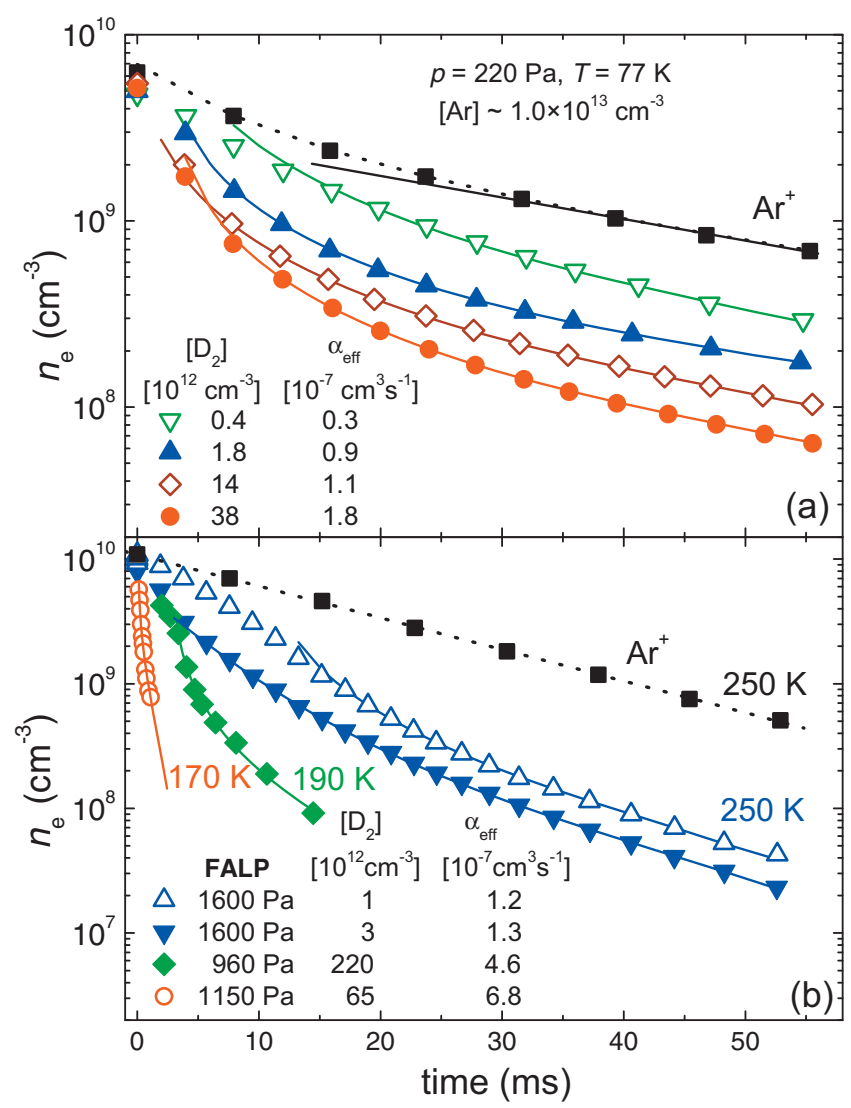

FIG. 1. Electron density decays measured in $\mathrm{D}_{3}^{+}$dominated afterglow plasma in the $\mathrm{He} / \mathrm{Ar} / \mathrm{D}_{2}$ mixture. (a) Data measured at $77 \mathrm{~K}$ and $220 \mathrm{~Pa}$. The decay curve measured in $\mathrm{Ar}^{+}$plasma is also given. (b) Data measured with several modifications of the FALP geometry. He pressures and temperatures are indicated. The decay curve measured in an $\mathrm{Ar}^{+}$plasma $(250 \mathrm{~K}$ with) is also shown.

on $[\mathrm{He}]$ is very small. At $77 \mathrm{~K}$ we have also measured decay of the $\mathrm{Ar}^{+}$dominated plasma [see panel (a) of Fig. 1]. If the plasma decay was due to ambipolar diffusion only, we would observe an exponential decay, similar to the one observed for $\mathrm{Ar}^{+}$ions at $250 \mathrm{~K}$ [the linear decay curve in semilogarithmic plot on panel (b) of Fig. 1]. The faster decay in the early afterglow indicates an additional loss mechanism. We assign it to the process of collisional radiative recombination (CRR) of $\mathrm{Ar}^{+}$ions. ${ }^{68,69}$ The obtained ternary rate coefficient from this fast decay is equal to the value calculated for the CRR rate coefficient at temperature $(85 \pm 10) \mathrm{K}$. This is an additional confirmation that the electron temperature in the afterglow plasma in Cryo-FALP is relaxed and is close to the buffer gas temperature ( $77 \mathrm{~K})$.

(2) $250 \mathrm{~K} ;$ AISA. Examples of data measured with AISA at 210 and $270 \mathrm{~Pa}$. The data were measured as a function of the deuterium density. ${ }^{7,39}$ FALP. Examples of data measured with FALP at pressure $1600 \mathrm{~Pa}$. Some decay curves are plotted in panel (b) of Fig. 1. Notice the large dependence on pressure.

(3) 77 and $250 \mathrm{~K}$ [and $300 \mathrm{~K}$ in panel (b)]; theory of $D R$. The $\alpha_{\text {DR }}$ have been calculated under the assumption that ions are in thermodynamic equilibrium. ${ }^{27,30}$

Panel (b) of Fig. 2:

(1) 170,190 , and $260 \mathrm{~K} ; F A L P$. The data were obtained at pressures 700-2000 $\mathrm{Pa}^{43}$ The experiment was aiming to understand recombination in a mixture of $\mathrm{D}_{3}^{+}$and $\mathrm{D}_{5}^{+}$ ions. By changing $\left[\mathrm{D}_{2}\right]$ the ratio $\left[\mathrm{D}_{3}^{+}\right] /\left[\mathrm{D}_{5}^{+}\right]$also changes. From the measured $\alpha_{\text {eff }}$ we obtained recombination rate coefficients for the both ions. ${ }^{43}$ To obtain $\alpha_{\text {eff }}$ for $\mathrm{D}_{3}^{+}$ions we used linear plots and the limit for $\left[\mathrm{D}_{2}\right] \rightarrow 0$ (see the inset).

(2) $300 \mathrm{~K} ;$ Cryo-FALP. $\alpha_{\text {eff }}$ measured over a limited interval of $\left[\mathrm{D}_{2}\right]$ at two He pressures (1020 and $1980 \mathrm{~Pa}$ ). In FALP experiments at $300 \mathrm{~K}$ of Gougousi et al. ${ }^{70}$ and Laubé et al. ${ }^{71}$ the data were obtained at relatively high $\left[\mathrm{D}_{2}\right]$ (see Fig. 3 in Ref. 46).

In the experiments the $\left[\mathrm{D}_{2}\right]$ was varied in the interval
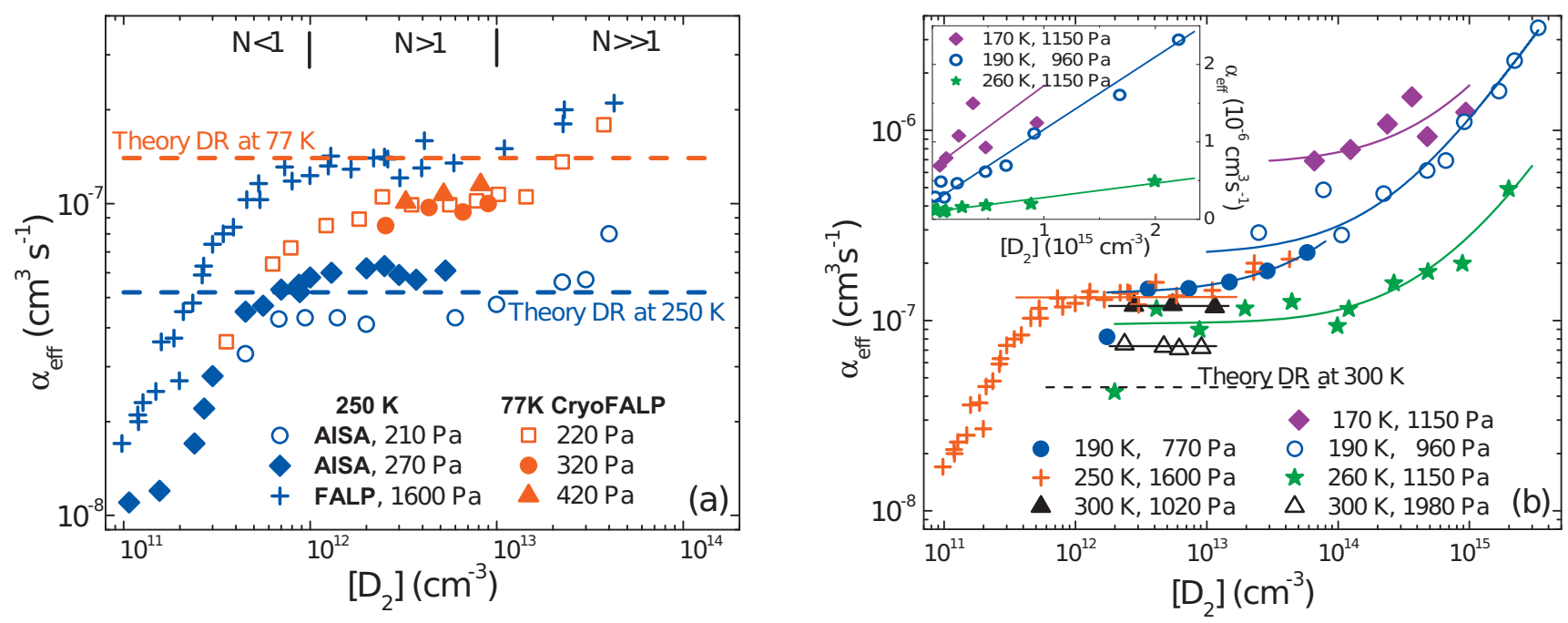

FIG. 2. $\mathrm{D}_{3}^{+}$effective binary recombination rate coefficient $\alpha_{\text {eff }}$ as a function of the deuterium density. (a) The data measured with Cryo-FALP (77 K), AISA $(250 \mathrm{~K})$ (Refs. 7 and 39) and FALP (250 K) (Ref. 45). (b) The FALP data obtained at 170, 190, 260, and $300 \mathrm{~K}$ (high [ $\left.\mathrm{D}_{2}\right]$ ). The inset shows the same plot on a linear scale. Such plots were used for the linear extrapolation toward low $\left[\mathrm{D}_{2}\right]$ corresponding to "region of saturation" (Ref. 43). The FALP data with low $\left[\mathrm{D}_{2}\right]$ are also shown $(250 \mathrm{~K})$. The theoretical values of DR rate coefficient $\alpha_{\mathrm{DR}}$ for 77,250 , and $300 \mathrm{~K}$ are also plotted (Ref. 30 ). 


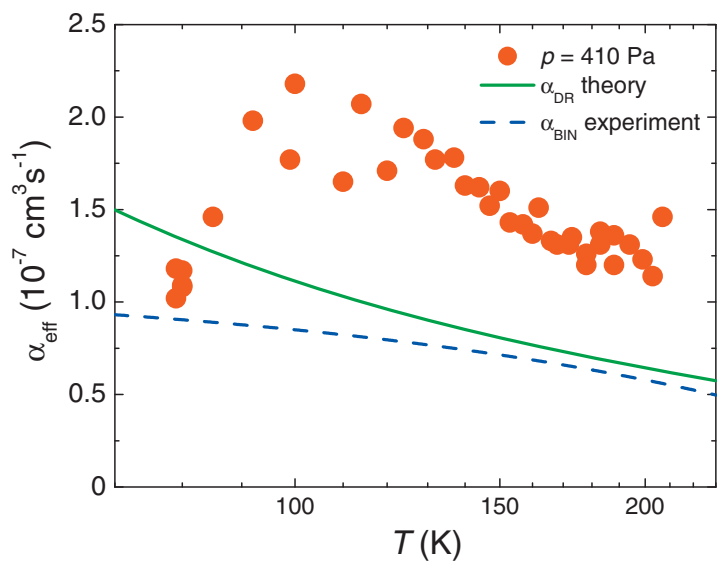

FIG. 3. The effective recombination rate coefficient $\left(\alpha_{\text {eff }}\right)$ measured in the Cryo-FALP experiment with continuous slow increase of temperature. The partial pressures of $\mathrm{He}$ and $\mathrm{D}_{2}$ were kept constant during the measurements. The densities at $77 \mathrm{~K}$ are $[\mathrm{He}]=3.8 \times 10^{17} \mathrm{~cm}^{-3}$ and $\left[\mathrm{D}_{2}\right]=2.6$ $\times 10^{12} \mathrm{~cm}^{-3}$. The theoretical $\alpha_{\mathrm{DR}}$ (Refs. 27 and 30) and experimental $\alpha_{\text {Bin }}$ values for the binary electron- $\mathrm{D}_{3}^{+}$dissociative recombination are also given.

$10^{11} \mathrm{~cm}^{-3}<\left[\mathrm{D}_{2}\right]<10^{15} \mathrm{~cm}^{-3}$. In certain measurements $\alpha_{\mathrm{eff}}$ was measured only over a limited interval of $\left[\mathrm{D}_{2}\right]$. Figure 2 provides information on the dependence of $\alpha_{\text {eff }}$ on temperature and on $[\mathrm{He}]$ and $\left[\mathrm{D}_{2}\right]$. It is evident from Fig. 2 that the measured dependencies on $\left[\mathrm{D}_{2}\right]$ clearly reveal three regions with specific dependencies of $\alpha_{\text {eff }}$ on [ $\left.\mathrm{D}_{2}\right]$. In addition, we can see clear dependencies of $\alpha_{\text {eff }}$ on [He] and on temperature.

Below, we discuss recombination in plasma at such $\left[\mathrm{D}_{2}\right]$ for which $\alpha_{\text {eff }}$ is nearly independent on $\left[\mathrm{D}_{2}\right]$, i.e., $10^{12} \mathrm{~cm}^{-3}<\left[\mathrm{D}_{2}\right]<10^{14} \mathrm{~cm}^{-3}$, "the region of saturation." At such $\left[\mathrm{D}_{2}\right]$ the $\mathrm{D}_{3}^{+}$ion undergoes several collisions with $\mathrm{D}_{2}$ before it recombines with an electron. To demonstrate this we compare the characteristic time for recombination with the characteristic time of interaction with $\mathrm{D}_{2}$. The number of interactions with $\mathrm{D}_{2}$, in Fig. 2(a) indicated by $N$, could be estimated if we consider only the collisions leading to a change in the nuclear spin of $\mathrm{D}_{3}^{+}$, for which the rate coefficients are known, ${ }^{9,30,72} k_{\mathrm{SCH}} \approx 2 \times 10^{-10} \mathrm{~cm}^{3} \mathrm{~s}^{-1}$. The frequency $\nu_{\mathrm{SCH}}$ of these reactions at $\left[\mathrm{D}_{2}\right]=10^{12} \mathrm{~cm}^{-3}$ is $\nu_{\mathrm{SCH}}$ $=k_{\mathrm{SCH}} \times\left[\mathrm{D}_{2}\right] \approx 200 \mathrm{~s}^{-1}$. If we use $\alpha_{\mathrm{eff}} \approx 1 \times 10^{-7} \mathrm{~cm}^{3} \mathrm{~s}^{-1}$, the recombination frequency is $\nu_{\mathrm{rec}}=\alpha_{\mathrm{eff}} \times n_{\mathrm{e}} \approx 200 \mathrm{~s}^{-1}$ at the typical FALP conditions where $n_{\mathrm{e}} \approx 2 \times 10^{9} \mathrm{~cm}^{-3}$. For $\left[\mathrm{D}_{2}\right]>10^{12} \mathrm{~cm}^{-3}$ and $n_{\mathrm{e}}<2 \times 10^{9} \mathrm{~cm}^{-3}$ we obtain $\nu_{\mathrm{SCH}}>\nu_{\text {rec. }}$.

Using Cryo-FALP we have also carried out measurements, in which the flow tube was first cooled by liquid nitrogen down to $77 \mathrm{~K}$ and then the flow of liquid nitrogen was stopped and the temperature of the flow tube was slowly increasing up to $210 \mathrm{~K}$. At fixed buffer gas pressure $\alpha_{\text {eff }}$ was measured as a function of the actual flow tube temperature. The obtained data are plotted in Fig. 3. A sharp increase of $\alpha_{\text {eff }}$ with the increasing temperature starting from $77 \mathrm{~K}$ was observed. When the temperature becomes larger than $\approx 100 \mathrm{~K}, \alpha_{\text {eff }}$ starts to decrease.

\section{ANALYSIS OF THE EXPERIMENTAL RESULTS}

In this section we analyze the dependence of $\alpha_{\text {eff }}$ on [He] in the "region of saturation," $10^{12} \mathrm{~cm}^{-3}<\left[\mathrm{D}_{2}\right]<10^{14} \mathrm{~cm}^{-3}$.

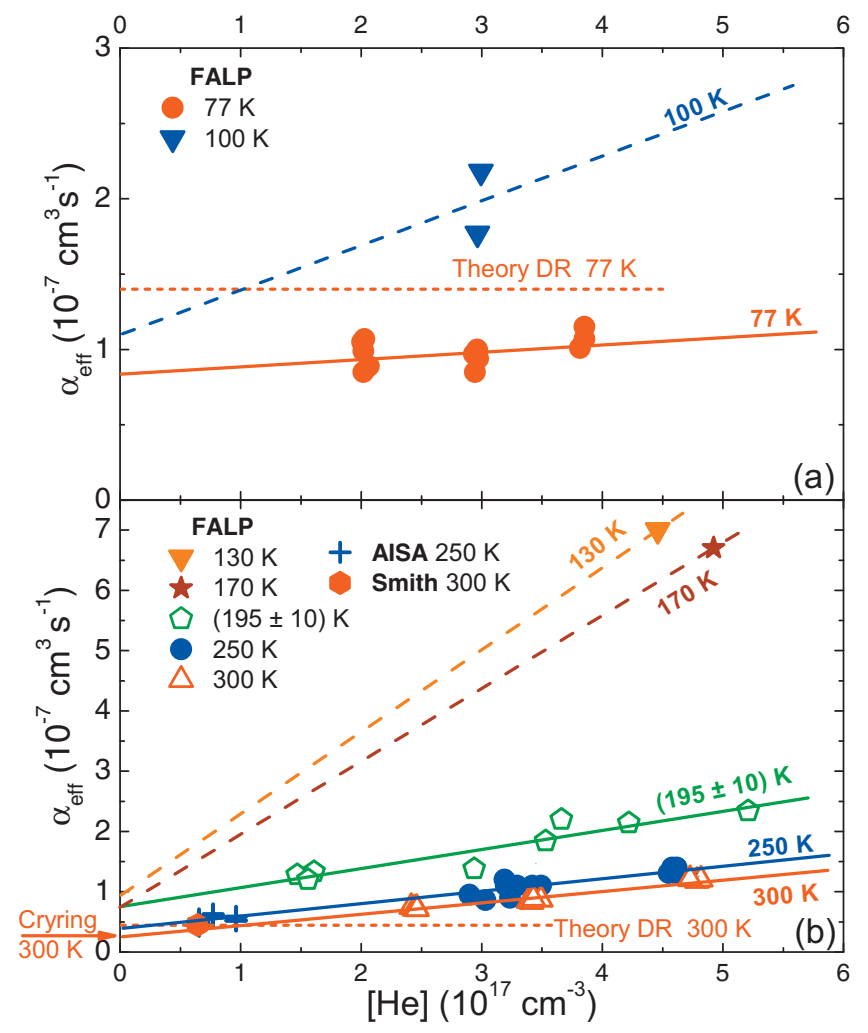

FIG. 4. Dependencies of the effective binary recombination rate coefficient $\left(\alpha_{\text {eff }}\right)$ on $[\mathrm{He}]$ measured at different temperatures. The data were obtained at deuterium densities: $10^{12} \mathrm{~cm}^{-3}<\left[\mathrm{D}_{2}\right]<10^{14} \mathrm{~cm}^{-3}$ (region of saturation). The figures includes also the data from previous AISA experiments (Ref. 39) and the value obtained by Smith and Spanel in a FALP experiment (Ref. 17). Data for 250, 300, and partly for $195 \mathrm{~K}$ are taken from Ref. 46. Theoretical values for 300 and $77 \mathrm{~K}$ are indicated by horizontal dashed lines (Ref. 30). The experimental value (Refs. 73 and 74) obtained in CRYRING and corresponding to $300 \mathrm{~K}$ is indicated by an arrow (Cryring $300 \mathrm{~K}$ ).

In order to obtain the dependence of $\alpha_{\text {eff }}$ on [He], we plotted $\alpha_{\text {eff }}$ measured at a constant temperature versus [He] (see Fig. 4). At 250 and $300 \mathrm{~K}$, we measured the dependence of $\alpha_{\text {eff }}$ on [He] explicitly [see panel (b) in Fig. 4]. For $(195 \pm 10) \mathrm{K}$ we have performed several measurements, including the one obtained directly as a function of [He]. On the corresponding plots we can see a clear linear dependence of $\alpha_{\text {eff }}$ on [He] (full straight lines). The dependence of $\alpha_{\text {eff }}$ on $[\mathrm{He}]$ at $77 \mathrm{~K}$ was also measured explicitly. For temperatures 100, 130, and $170 \mathrm{~K}$, we have measured $\alpha_{\text {eff }}$ only for certain values of [He].

If we assume that the $\mathrm{D}_{3}^{+}$-dominated plasma recombination is governed by the binary $\left(\mathrm{D}_{3}^{+}+e^{-}\right)$and ternary $\left(\mathrm{D}_{3}^{+}+e^{-}+\mathrm{He}\right)$ processes, the effective recombination rate can be represented as

$$
\alpha_{\text {eff }}=\alpha_{\text {Bin }}(T)+K_{\mathrm{He}}(T) \cdot[\mathrm{He}],
$$

where $\alpha_{\mathrm{Bin}}(T)$ is the effective rate coefficient for the binary recombination and $K_{\mathrm{He}}(T)$ is the effective rate coefficient for the ternary recombination.

The $\alpha_{\text {Bin }}$ obtained from the measured [He]-dependencies of $\alpha_{\text {eff }}$ (solid lines in Fig. 4) are plotted in Fig. 5 as a function of temperature. The agreement between the measured value $\alpha_{\mathrm{Bin}}(T)$, the calculated value $\alpha_{\mathrm{DR}}(T)$, and the CRYRING data is very good. A linear extrapolation of the measured $\alpha_{\mathrm{Bin}}(T)$ 


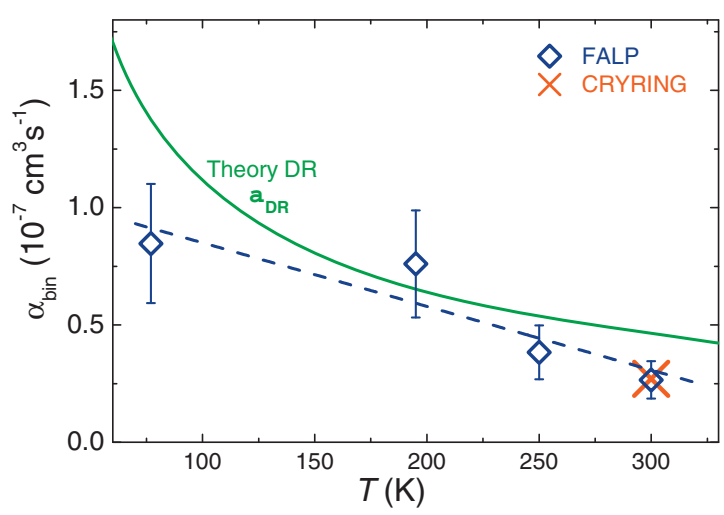

FIG. 5. $\mathrm{D}_{3}^{+}$binary recombination rate coefficients. The solid line indicates the calculated values for the binary dissociative recombination $\left(\alpha_{\mathrm{DR}}\right)$ at a thermal population of the para-/ortho-/metastates of $\mathrm{D}_{3}^{+}$(Ref. 30). The values $\alpha_{\text {Bin }}$ (diamonds) were obtained from measured $\alpha_{\text {eff }}(T,[\mathrm{He}])$. The dashed line is a fit to the experimental data. The experimental value (Refs. 73 and 74) from the CRYRING experiment is shown by a cross $(X)$.

has been used to derive $K_{\mathrm{He}}(T)$ from the measured $\alpha_{\text {eff }}(T)$ (see dashed lines in Fig. 4). The obtained values of $K_{\mathrm{He}}(T)$ are plotted in Fig. 6 as a function of temperature. We briefly summarize the data plotted in Fig. 6.

(1) $77 \mathrm{~K}$; Cryo-FALP (closed diamond). Data obtained in the present experiments by measuring the pressure dependence of $\alpha_{\text {eff }}$ at $77 \mathrm{~K}$ (see Fig. 4). Actually, we have observed only a very small pressure dependence $K_{\mathrm{He}}(77 \mathrm{~K}) \approx 0.5 \times 10^{-25} \mathrm{~cm}^{6} \mathrm{~s}^{-1}$.

(2) 130 and $170 \mathrm{~K}$; FALP (triangles). The experiments were carried out using the flow tube with a small diameter. A fast flow of the buffer gas is well suited for studying fast plasma decays (see decay curve for $170 \mathrm{~K}$ in Fig. 1). We have measured the dependence of $\alpha_{\text {eff }}$ on $\left[\mathrm{D}_{2}\right]$ but only at one fixed [He]. To obtain $K_{\mathrm{He}}$, we have used the extrapolated value of $\alpha_{\mathrm{Bin}}(T)$ as discussed above (the dashed line in Fig. 5).

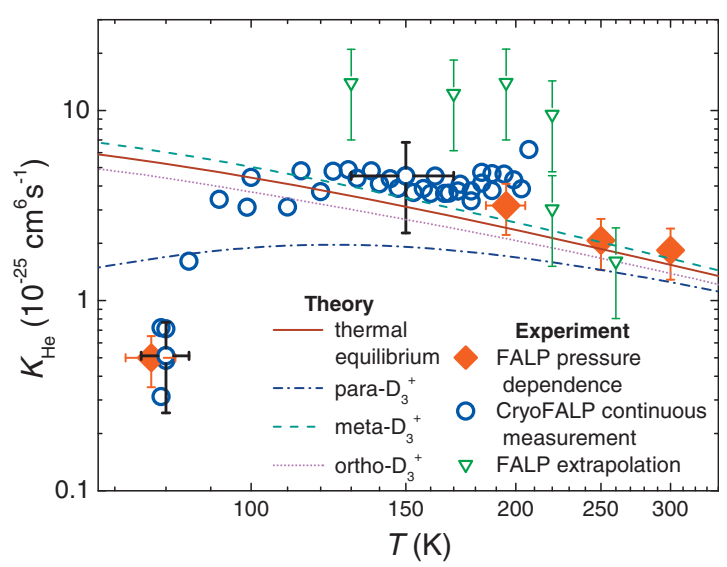

FIG. 6. The ternary recombination rate coefficient, $K_{\mathrm{He}}(T)$, for He assisted recombination of $\mathrm{D}_{3}^{+}$ions. The values obtained from the measured linear dependencies of effective recombination rate coefficient on [He] (see full lines in Fig. 4) are indicated by diamonds. The values of $K_{\mathrm{He}}$ obtained at a fixed He density and a fixed temperature using the extrapolated values of $\alpha_{\mathrm{Bin}}(T)$ are shown by triangles. The data measured with Cryo-FALP with the continuously increasing temperature are indicated by circles (see the text and Fig. 3). We have also specified theoretical ternary rate coefficients for ortho-, para-, and meta- $\mathrm{D}_{3}^{+}$as well as the value calculated for the thermal ortho-/para-/meta- $\mathrm{D}_{3}^{+}$equilibrium (Ref. 46).
(3) 190, 220, and $260 \mathrm{~K}$; FALP (triangles). $\alpha_{\text {eff }}$ measured in different experiments (see Fig. 2, panel b). To obtain $K_{\mathrm{He}}$ we have used $\alpha_{\mathrm{Bin}}(T)$.

(4) 195, 250, and $300 \mathrm{~K}$; FALP (closed diamonds). The data from the pressure dependence of $\alpha_{\text {eff }}$, see panel (b) of Fig. 4 (see also Ref. 46).

(5) 77-210 K; "Continuous measurement" with CryoFALP (open circles). We measured $\alpha_{\text {eff }}(T)$ by continuously increasing the flow tube temperature. From the measured $\alpha_{\text {eff }}(T)$ we calculated $K_{\mathrm{He}}(T)$ using $\alpha_{\mathrm{Bin}}(T)$.

The ternary recombination rate coefficients calculated for different spin states are also plotted in the Fig. 6. The calculated and measured values are in good agreement at temperatures above $100 \mathrm{~K}$. The sharp increase of $K_{\mathrm{He}}$ observed at temperatures below $100 \mathrm{~K}$ is somewhat surprising when comparing with previous studies of ternary association processes, ${ }^{48,61,75}$ in which the monotone decrease, $K \sim T^{-n}$, was usually observed. We can also refer to other measurements ${ }^{69,76}$ of ternary recombination rate coefficients in which the electron played the role of a third body. In these studies a steep decrease of the rate coefficient with the temperature was observed (CRR, $K \sim T^{-9 / 2}$ ). The measured rise of $K_{\mathrm{He}}$ is not understood yet.

\section{THEORETICAL MODEL FOR HELIUM-ASSISTED TERNARY RECOMBINATION OF $\mathrm{D}_{3}^{+}$}

The theory of the ternary helium assisted recombination of $\mathrm{H}_{3}^{+}$and $\mathrm{D}_{3}^{+}$ions has been developed and described in our earlier papers ${ }^{44-46}$ for the $\mathrm{D}_{3}^{+}$recombination. We will give only a short summary here. Low-energy $(0-0.3 \mathrm{eV})$ collisions between an electron and $\mathrm{H}_{3}^{+}\left(\right.$or $\mathrm{D}_{3}^{+}$) can lead to the rotational excitation of the ion with an appreciable probability (see Table VI in Ref. 27) if the kinetic energy of the incident electron is large enough to excite the ion rotationally. The large probability is caused by a strong coupling between the rotating ionic core $\left(\mathrm{H}_{3}^{+}\right.$or $\left.\mathrm{D}_{3}^{+}\right)$and the motion of the incident electron. For a given total angular momentum $N$ of the ion+electron system, the scattering amplitude for a $p$-wave electron incident on the ion depends strongly on the projection $\Lambda=0, \pm 1$ ( $p \sigma$ and $p \pi$ electronic states) of the electronic angular momentum $(l=1)$ on the molecular symmetry axis. When the electron is close to the ion, the energy of the system is determined by the electronic states of the molecule. Correspondingly, the scattering matrix is diagonal if one considers the scattering from the ion with clumped nuclei. At an infinite separation between the ion and the electron, the appropriate scattering channels are determined not by $\Lambda$ but by the rotational states of the ionic core, i.e., by quantum numbers $\left(N^{+}, K^{+}\right)$. Here and below $N^{+}$and $K^{+}$are the angular momentum of the ion and its projection on the molecular symmetry axis. The quantum states with definite $\left(N^{+}, K^{+}\right)$are linear combinations of states with different $\Lambda$. Our treatment here considers only rotational transitions (without changing the vibrational level of the ion, which is assumed to be the lowest vibrational level). In this situation, the states with definite $\left(N^{+}, K^{+}\right)$and $\Lambda$ are linked to each other by Clebsch-Gordan coefficients (rotational frame transformation). For more detail, see Refs. 27 and 32. Be- 
cause the scattering matrix at small ion-electron separations is diagonal with very different diagonal elements (we do not consider here the Jahn-Teller physics, which is inactive if the initial and final vibrational levels of the ion are the same), the scattering matrix in the representation describing the $N^{+} \rightarrow N^{+^{\prime}}= \pm 1$ or $N^{+} \pm 2$ change in the rotational state has appreciable nondiagonal matrix elements. Therefore, the probability for the $N^{+} \rightarrow N^{+^{\prime}}= \pm 1$ or $N^{+} \pm 2$ transitions could be comparable to the unity. If the ion is in its lowest rotational state and the electronic kinetic energy is not sufficient for such a $N^{+} \rightarrow{N^{+}}^{\prime}$ transition, the large difference in the scattering phases between $p \pi$ and $p \sigma$ states is transformed into a large probability of transition from the open $\left(N^{+}\right)$into the closed $\left(N^{+^{\prime}}\right)$ channel. In such a situation, the presence of a closed channel is manifested as an appearance of a series of autoionizing Rydberg resonances (Beutler-Fano resonances) with large widths in spectra of different observables (such as photoionization). The series converges to the closed $\left(N^{+^{\prime}}\right)$ channel. Such a situation with the $\mathrm{H}_{3}^{+}$ion has been observed in photoionization experiments of Helm. ${ }^{77,78}$ In these experiments, the Beutler-Fano photoionization parts of the spectrum [between the two coupled rotational levels, (10) and (30), of $\mathrm{H}_{3}^{+}$] demonstrate a series of wide Beutler-Fano resonances ${ }^{79}$ with widths comparable to the energy difference between the two consecutive resonances. The fact that the widths are comparable with the energy difference between the resonances means that the probability for $N^{+} \rightarrow N^{+^{\prime}}$ transitions in electron-ion collisions is comparable to unity. The theoretical photoionization spectra based on this concept ${ }^{77,78,80}$ agree well with the experimental data.

From a time-dependent point of view, the appearance of resonances in spectra corresponds to a long $\mathrm{D}_{3}^{+}+e^{-}$collision time. For collision energies between two coupled rotational levels of $\mathrm{D}_{3}^{+}$[for example between the (00) and (20) levels], the delay time in electron-ion collisions is increased and may be long enough to be comparable with the time between two consecutive collisions of the $\mathrm{D}_{3}^{+}+e^{-}$system with background helium atoms. From a time-independent point of view, in a low-temperature gas containing electrons and $\mathrm{D}_{3}^{+}$ions, the probability that a helium atom collides with a weakly bound $\mathrm{D}_{3}^{*}$ Rydberg molecule is significant because the electronic probability density in $\mathrm{D}_{3}^{*}$ is greatly increased near the ionic core due to the strong interaction of the closed channel of the $\mathrm{D}_{3}^{*}$ complex with the entrance channel of the $\mathrm{D}_{3}^{+}+e^{-}$system.

As a result of this qualitative view of the process, we have developed in Refs. 44-46 a two-step model for the helium-assisted recombination of $\mathrm{D}_{3}^{+}\left(\right.$and $\left.\mathrm{H}_{3}^{+}\right)$with electrons. First, $\mathrm{D}_{3}^{+}$and an $e^{-}$collide and form a rotationally autoionizing resonance $\mathrm{D}_{3}^{*}(n p)$. Then a collision with a helium atom changes the electron state of $\mathrm{D}_{3}^{*}(n p)$ to a state $\mathrm{D}_{3}^{*}(n l)$ with a different $(l \neq 1)$ electronic angular momentum that makes autoionization impossible and eventually leads to the dissociation. This can be written as

(step 1) $\mathrm{D}_{3}^{+}+e^{-} \rightarrow \mathrm{D}_{3}(n p)$,

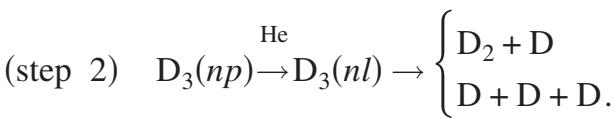

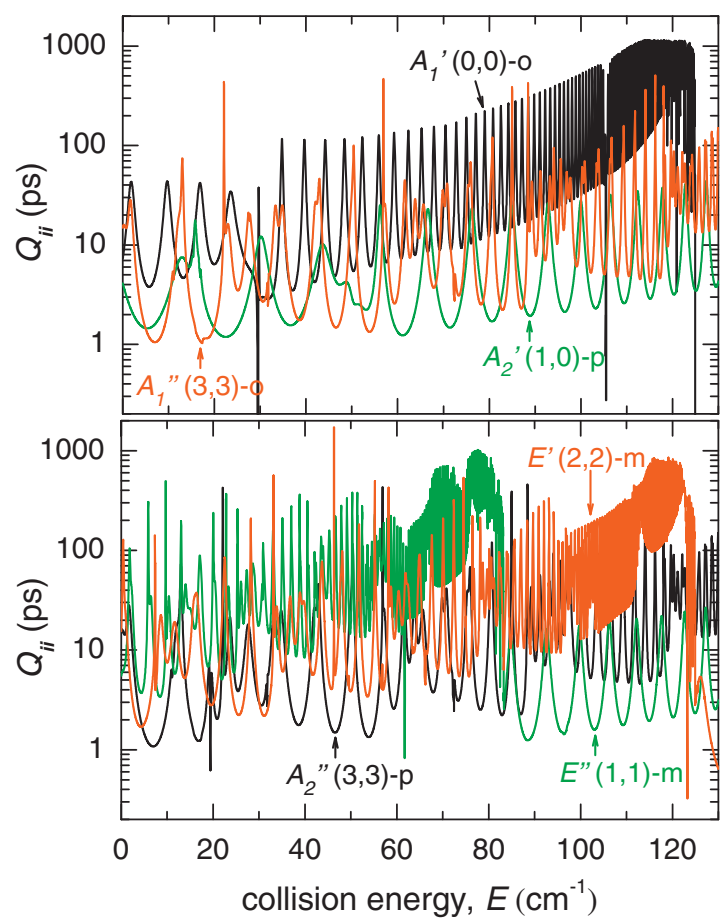

FIG. 7. The diagonal elements $Q_{i i}\left(E_{1}\right)$ of Smith's lifetime matrix calculated from the scattering matrix as discussed in Ref. 46 for the six different irreducible representations of the $K_{\mathrm{He}}(T)$ system. Each of the six curves shown in the figure is labeled with the corresponding symbol of irreducible representation $\left(A_{1}^{\prime}, A_{2}^{\prime}\right.$, etc. $)$ and the rotational quantum numbers $\left(N^{+}, K^{+}\right)$of the ion followed by $-0,-\mathrm{m}$, or -p (for ortho-, meta-, or para- $\mathrm{D}_{3}^{+}$).

The rate constant $K_{i}^{3 \mathrm{D}}\left(E_{1}, E_{2}\right)$ for the two-step process above depends on the energy $E_{1}$ of collision between $e^{-}$and $\mathrm{D}_{3}^{+}$, on the energy $E_{2}$ of collision between $\mathrm{D}_{3}^{*}$ and $\mathrm{He}$, and on the initial state $|i\rangle$ of $\mathrm{D}_{3}^{+}$. The formula for $K_{i}^{3 \mathrm{D}}\left(E_{1}, E_{2}\right)$ is derived in Ref. 45 (in a.u.),

$$
K_{i}^{3 \mathrm{D}}\left(E_{1}, E_{2}\right)=\frac{\pi}{\sqrt{2 E_{1}}} Q_{i i}\left(E_{1}\right) k^{l}\left(E_{2}\right)
$$

where $Q_{i i}\left(E_{1}\right)$ is the diagonal element of Smith's lifetime matrix, ${ }^{81} k^{l}\left(E_{2}\right)$ is the rate constant for the second step of the process, $k^{l}\left(E_{2}\right)=\sqrt{2 E_{2} / m_{2}} \sigma\left(E_{2}\right), \sigma\left(E_{2}\right)$ is the cross-section for the second reaction in Eq. (4), and $m_{2}$ is the reduced mass of the $\mathrm{D}_{3}^{*}$-He system.

The lifetime matrix elements $Q_{i i}\left(E_{1}\right)$ in Eq. (5) depend strongly on the energy $E_{1}$ and on the initial state of the electron-ion system. A few examples of the energydependence of $Q_{i i}\left(E_{1}\right)$ for several different initial states $|i\rangle$ are shown in Fig. 7. The figure shows the $Q_{i i}\left(E_{1}\right)$ elements for the all six irreducible representations of the $\mathrm{D}_{3}^{+}+e^{-}$system $\left(A_{1}^{\prime}, A_{1}^{\prime \prime}, A_{2}^{\prime}, A_{2}^{\prime \prime}, E^{\prime}\right.$, and $\left.E^{\prime \prime}\right)$ at low collisional energies. Most of the resonances shown are due to the Rydberg series of autoionizing electronic states converging to the first excited rotational state of the corresponding irreducible representation. As one can see from the figure, in addition to the regular Rydberg series of resonances, there are resonances perturbing the series. These perturbers belong to highly excited ionization limits.

In order to compare theory with the present experiment, the rate constant $K_{i}^{3 \mathrm{D}}$ should be averaged with respect to 
Maxwell-Boltzmann distributions over collisional energies $E_{1}$ and $E_{2}$, and with respect to initial population of ionic states $|i\rangle$ at a given temperature $T$,

$$
\left\langle K^{3 \mathrm{D}}\right\rangle=\sqrt{\frac{2 \pi}{\left(k_{\mathrm{B}} T\right)^{3}}} \frac{k^{l} \sum_{i} \int_{0}^{\infty} Q_{i i}\left(E_{1}\right) w_{i} \exp \left(-E_{1}+E_{i} / k_{\mathrm{B}} T\right) \mathrm{d} E_{1}}{\sum_{i} w_{i} \exp \left(-E_{i} / k_{\mathrm{B}} T\right)},
$$

where $k^{l}=k^{l}\left(E_{2}\right)$ is assumed to be energy independent, $w_{i}$ and $E_{i}$ are the statistical weight and energy of the initial state $|i\rangle$ of the $\mathrm{D}_{3}^{+}$ion, and $k_{\mathrm{B}}$ is the Boltzmann constant. ${ }^{45}$ The thermally averaged rate coefficient $\left\langle K^{3 \mathrm{D}}\right\rangle$ obtained is shown in Fig. 6.

\section{DISCUSSION AND CONCLUSIONS}

This is the fourth in the present series of papers devoted to the study of ternary and binary recombinations of $\mathrm{H}_{3}^{+}$and $\mathrm{D}_{3}^{+}$ions with electrons. In previous papers we described experimental data for $\mathrm{H}_{3}^{+}$recombination and data for $\mathrm{D}_{3}^{+}$recombination at $200-300 \mathrm{~K}^{46}$ In the present paper we have extended the previous $\mathrm{D}_{3}^{+}$study down to $77 \mathrm{~K}$. The binary recombination rate coefficients measured in the present experiments are in good agreement with data calculated for binary dissociative recombination ${ }^{27,28,30}$ and with available storage ring data. ${ }^{73,74}$

We have also developed the theoretical model describing process of the observed helium assisted ternary recombination. In this model we consider the helium-assisted recombination as a two-step process (two rate determining steps). First, the ion and electron collide forming a relatively longliving autoionizing resonance $\mathrm{D}_{3}^{*}(n p)$ with the rotationally excited ionic core. Then a collision with a helium atom changes the electronic state of $\mathrm{D}_{3}^{*}(n p)$ to a state $\mathrm{D}_{3}^{*}(n l)$ with a different $(l \neq 1)$ electronic angular momentum. To support this model we calculated lifetime (delay time) of $\mathrm{D}_{3}^{*}(n p)$ formed in electron-ion interaction. Calculations showed that at temperatures $77-300 \mathrm{~K}$ the lifetime can be as large as a few hundreds of picoseconds. The obtained delay times were used to calculate ternary recombination rate coefficients and their temperature dependence. The calculated values are in agreement with the measured values at higher temperatures $(100-300 \mathrm{~K})$ but the theoretical model does not describe correctly the observed suppression of ternary recombination at lower temperatures. The disagreement might indicate that at low temperatures the rate coefficients $k^{l}$ are not energy independent (see, e.g., theory and compilation of data by Hickman in Ref. 82).

There are still many open questions concerning the process of recombination of $\mathrm{H}_{3}^{+}$and $\mathrm{D}_{3}^{+}$ions. One of the most important questions now is the state selectivity at low temperatures.

\section{ACKNOWLEDGMENTS}

This work is a part of the research plan MSM 0021620834 financed by the Ministry of Education of the Czech Republic and was partly supported by GACR (202/07/ 0495, 202/08/H057, 205/09/1183, 202/09/0642), by GAUK 86908, GAUK 25709, GAUK 53607, GAUK 124707, by the
National Science Foundation Grant No. PHY-0855622, by the Department of Energy Office of Science, and by an allocation of NERSC supercomputing resources. V.K. also acknowledges the support from the RTRA "Triangle de la Physique" contract QCCM.

${ }^{1}$ T. Oka, Philos. Trans. R. Soc. London, Ser. A 358, 2363 (2000).

${ }^{2}$ E. Herbst, Philos. Trans. R. Soc. London, Ser. A 358, 2523 (2000).

${ }^{3}$ R. Johnsen, J. Phys.: Conf. Ser. 4, 83 (2005).

${ }^{4}$ E. Shkolnik, E. Gaidos, and N. Moskovitz, Astrophys. J. 132, 1267 (2006).

${ }^{5} \mathrm{M}$. Larsson and A. Orel, Dissociative Recombination of Molecular Ions (Cambridge University Press, New York, 2008).

${ }^{6}$ J. Glosík, R. Plasil, V. Poterya, P. Kudrna, and M. Tichy, Chem. Phys. Lett. 331, 209 (2000).

${ }^{7}$ R. Plasil, J. Glosik, V. Poterya, P. Kudrna, J. Rusz, M. Tichy, and A. Pysanenko, Int. J. Mass Spectrom. 218, 105 (2002).

${ }^{8}$ T. R. Geballe and T. Oka, Science 312, 1610 (2006).

${ }^{9}$ D. Gerlich, F. Windish, P. Hlavenka, R. Plasil, and J. Glosik, Philos. Trans. R. Soc. London, Ser. A 364, 3007 (2006).

${ }^{10}$ M. Larsson, B. McCall, and A. E. Orel, Chem. Phys. Lett. 462, 145 (2008).

${ }^{11}$ T. Oka, Phys. Rev. Lett. 45, 531 (1980).

${ }^{12}$ L. Trafton, D. Lester, and K. Thompson, Astrophys. J. 343, L73 (1989).

${ }^{13}$ S. Miller, J. Tennyson, S. Lepp, and A. Dalgarno, Nature (London) 355, 420 (1992).

${ }^{14}$ T. Geballe and T. Oka, Nature (London) 384, 334 (1996).

${ }^{15}$ N. G. Adams, D. Smith, and E. Alge, J. Chem. Phys. 81, 1778 (1984).

${ }^{16}$ T. Amano, Astrophys. J. 329, L121 (1988).

${ }^{17}$ D. Smith and P. Spanel, Int. J. Mass Spectrom. Ion Process. 129, 163 (1993).

${ }^{18}$ R. Johnsen and J. Mitchell, in Advances in Gas Phase Ion Chemistry, Vol. 3, edited by N. G. Adams and L. M. Babcock (JAI Press, Greenwich, CT, 1998), p. 49.

${ }^{19}$ A. Orel, I. Schneider, and A. Suzor-Weiner, Philos. Trans. R. Soc. London, Ser. A 358, 2445 (2000).

${ }^{20}$ D. Smith and P. Spanel, Chem. Phys. Lett. 211, 454 (1993).

${ }^{21}$ T. Amano, J. Chem. Phys. 92, 6492 (1990).

${ }^{22}$ N. Feher, A. Rohrbacher, and J. P. Maier, Chem. Phys. 185, 357 (1994).

${ }^{23}$ P. Macko, G. Bano, P. Hlavenka, R. Plasil, V. Poterya, A. Pysanenko, O. Votava, R. Johnsen, and J. Glosik, Int. J. Mass Spectrom. 233, 299 (2004).

${ }^{24}$ J. Glosik, P. Hlavenka, R. Plasil, F. Windisch, D. Gerlich, A. Wolf, and H. Kreckel, Philos. Trans. R. Soc. London, Ser. A 364, 2931 (2006).

${ }^{25}$ V. Kokoouline, C. H. Greene, and B. D. Esry, Nature (London) 412, 891 (2001).

${ }^{26}$ V. Kokoouline and C. H. Greene, Phys. Rev. Lett. 90, 133201 (2003).

${ }^{27}$ V. Kokoouline and C. H. Greene, Phys. Rev. A 68, 012703 (2003).

${ }^{28}$ C. Jungen and S. T. Pratt, Phys. Rev. Lett. 102, 023201 (2009).

${ }^{29}$ S. Fonseca dos Santos, V. Kokoouline, and C. H. Greene, J. Chem. Phys. 127, 124309 (2007).

${ }^{30}$ L. Pagani, C. Vastel, E. Hugo, V. Kokoouline, C. H. Greene, A. Bacmann, E. Bayet, C. Ceccarelli, R. Peng, and S. Schlemmer, Astron. Astrophys. 494, 623 (2009).

${ }^{31}$ V. Kokoouline and C. H. Greene, J. Phys.: Conf. Ser. 4, 74 (2005).

${ }^{32}$ A. Faure, V. Kokoouline, C. H. Greene, and J. Tennyson, J. Phys. B 39, 4261 (2006).

${ }^{33}$ A. Faure, J. Tennyson, V. Kokoouline, and C. H. Greene, J. Phys.: Conf. Ser. 192, 012016 (2009).

${ }^{34}$ V. Kokoouline, A. Faure, J. Tennyson, and C. H. Greene, Mon. Not. R. Astron. Soc. 405, 1195 (2010).

${ }^{35}$ B. J. McCall, A. J. Huneycutt, R. J. Saykally, T. R. Geballe, N. Djuric, G. H. Dunn, J. Semaniak, O. Novotny, A. Al-Khalili, A. Ehlerding, F. Hellberg, S. Kalhori, A. Neau, R. Thomas, F. Osterdahl, and M. Larsson, Nature (London) 422, 500 (2003).

${ }^{36}$ H. Kreckel, M. Motsch, J. Mikosch, J. Glosik, R. Plasil, S. Altevogt, V. Andrianarijaona, H. Buhr, J. Hoffmann, L. Lammich, M. Lestinsky, I. Nevo, S. Novotny, D. A. Orlov, H. B. Pedersen, F. Sprenger, A. S. Terekhov, J. Toker, R. Wester, D. Gerlich, D. Schwalm, A. Wolf, and D. Zajfman, Phys. Rev. Lett. 95, 263201 (2005).

${ }^{37}$ A. Wolf, H. Kreckel, L. Lammich, D. Strasser, J. Mikosch, J. Glosik, R. Plasil, S. Altevogt, V. Andrianarijaona, H. Buhr, J. Hoffmann, M. Lestinsky, I. Nevo, S. Novotny, D. A. Orlov, H. B. Pedersen, A. S. Terekhov, J. 
Toker, R. Wester, D. Gerlich, D. Schwalm, and D. Zajfman, Philos. Trans. R. Soc. London, Ser. A 364, 2981 (2006).

${ }^{38}$ B. A. Tom, V. Zhaunerchyk, M. B. Wiczer, A. A. Mills, K. N. Crabtree, M. Kaminska, W. D. Geppert, M. Hamberg M. af Ugglas, E. Vigren, W. J. van der Zande, M. Larsson, R. D. Thomas, and B. J. McCall, J. Chem. Phys. 130, 031101 (2009).

${ }^{39}$ V. Poterya, J. Glosík, R. Plašil, M. Tichý, P. Kudrna, and A. Pysanenko, Phys. Rev. Lett. 88, 044802 (2002).

${ }^{40}$ J. Glosík, R. Plasil, V. Poterya, P. Kudrna, M. Tichy, and A. Pysanenko, J. Phys. B 34, L485 (2001)

${ }^{41}$ A. Pysanenko, O. Novotny, P. Zakouril, R. Plasil, V. Poterya, and J. Glosik, Czech. J. Phys. 52, D681 (2002).

${ }^{42}$ J. Glosík, O. Novotny, A. Pysanenko, P. Zakouril, R. Plasil, P. Kudrna, and V. Poterya, Plasma Sources Sci. Technol. 12, S117 (2003).

${ }^{43}$ O. Novotný, R. Plasil, A. Pysanenko, I. Korolov, and J. Glosik, J. Phys. B 39, 2561 (2006).

${ }^{44}$ J. Glosik, I. Korolov, R. Plasil, O. Novotny, T. Kotrik, P. Hlavenka, J. Varju, I. A. Mikhailov, V. Kokoouline, and C. H. Greene, J. Phys. B 41, 191001 (2008).

${ }^{45}$ J. Glosík, R. Plaŝil, I. Korolov, T. Kotrik, O. Novotný, P. Hlavenka, P. Dohnal, J. Varju, V. Kokoouline, and C. H. Greene, Phys. Rev. A 79, 052707 (2009).

${ }^{46}$ J. Glosík, I. Korolov, R. Plaŝili, T. Kotrik, P. Dohnal, O. Novotný, J. Varju, S. Roucka, C. H. Greene, and V. Kokoouline, Phys. Rev. A 80 042706 (2009).

${ }^{47}$ D. Gerlich and S. Horning, Chem. Rev. (Washington, D.C.) 92, 1509 (1992).

${ }^{48}$ J. Glosík, G. Bano, E. Ferguson, and W. Lindinger, Int. J. Mass Spectrom. 176, 177 (1998).

${ }^{49}$ K. Hiraoka and P. Kebarle, J. Chem. Phys. 62, 2267 (1975).

${ }^{50}$ J. Glosík, V. Skalsky, and W. Lindinger, Int. J. Mass Spectrom. Ion Process. 134, 67 (1994).

${ }^{51}$ G. Herzberg, Annu. Rev. Phys. Chem. 38, 27 (1987).

${ }^{52}$ T. Amano and M.-C. Chan, Philos. Trans. R. Soc. London, Ser. A 358 , 2457 (2000).

${ }^{53}$ M. Tashiro and S. Kato, J. Chem. Phys. 117, 2053 (2002).

${ }^{54}$ I. Mistrík, R. Reichle, H. Helm, and U. Müller, Phys. Rev. A 63, 042711 (2001).

${ }^{55}$ J. Thomson, Philos. Mag. 47, 337 (1924).

${ }^{56}$ D. R. Bates and S. P. Khare, Proc. Phys. Soc. London 85, 231 (1965).

${ }^{57}$ Y. S. Cao and R. Johnsen, J. Chem. Phys. 94, 5443 (1991).

${ }^{58}$ W. Wolfer, C. Bisson, P. Souers, and R. Tsugawa, Phys. Rev. A 41, 4470 (1990).
${ }^{59}$ G. Gousset, B. Sayer, and J. Berlande, Phys. Rev. A 16, 1070 (1977).

${ }^{60}$ A. Florescu-Mitchell and J. Mitchell, Phys. Rep. 430, 277 (2006).

${ }^{61}$ J. Glosík, P. Zakouril, V. Hanzal, and V. Skalský, Int. J. Mass Spectrom. Ion Process. 149-150, 187 (1995).

${ }^{62}$ J. Glosík, G. Bánó, R. Plasil, A. Luca, and P. Zakouril, Int. J. Mass Spectrom. 189, 103 (1999).

${ }^{63}$ I. Korolov, R. Plasil, T. Kotrik, P. Dohnal, O. Novotny, and J. Glosik, Contrib. Plasma Phys. 48, 461 (2008).

${ }^{64}$ J. Glosík, R. Plasil, A. Pysanenko, O. Novotný, P. Hlavenka, P. Macko, and G. Bánó, J. Phys.: Conf. Ser. 4, 104 (2005).

${ }^{65}$ J. D. Swift and M. J. R. Schwar, Electrical Probes for Plasma Diagnostics (Iliffe, London, 1970).

${ }^{66}$ I. Korolov, T. Kotrik, R. Plasil, J. Varju, M. Hejduk, and J. Glosik, Contrib. Plasma Phys. 48, 521 (2008).

${ }^{67}$ I. Korolov, R. Plasil, T. Kotrik, P. Dohnal, and J. Glosik, Int. J. Mass Spectrom. 280, 144 (2009).

${ }^{68}$ E. McDaniel, J. Mitchell, and M. Rudd, Atomic Collisions, Heavy Particle Projectiles (Wiley, New York, 1993).

${ }^{69}$ M. Skrzypkowski, R. Johnsen, R. Rosati, and M. Golde, Chem. Phys. 296, 23 (2004).

${ }^{70}$ T. Gougousi, R. Johnsen, and M. F. Golde, Int. J. Mass Spectrom. Ion Process. 149-150, 131 (1995).

${ }^{71}$ S. Laubé, A. Le Padellec, O. Sidko, C. Rebrion-Rowe, J. B. A. Mitchell, and B. R. Rowe, J. Phys. B 31, 2111 (1998).

${ }^{72}$ M. Cordonnier, D. Uy, R. M. Dickson, K. E. Kerr, Y. Zhang, and T. Oka, J. Chem. Phys. 113, 3181 (2000).

${ }^{73}$ M. Larsson, H. Danared, Å. Larson, A. Le Padellec, J. R. Peterson, S. Rosén, J. Semaniak, and C. Strömholm, Phys. Rev. Lett. 79, 395 (1997).

${ }^{74}$ A. Le Padellec, M. Larsson, H. Danared, Å. Larson, J. R. Peterson, S. Rosén, J. Semaniak, and C. Strömholm, Phys. Scr. 57, 215 (1998)

${ }^{75}$ N. G. Adams and D. Smith, Reactions of Small Transient Species (Academic, New York, 1983).

${ }^{76}$ D. R. Bates, A. E. Kingston, and R. W. P. McWhirter, Proc. R. Soc. London, Ser. A 267, 297 (1962).

${ }^{77}$ C. Bordas and H. Helm, Phys. Rev. A 43, 3645 (1991).

${ }^{78}$ I. Mistrík, R. Reichle, U. Müller, H. Helm, M. Jungen, and J. Stephens, Phys. Rev. A 61, 033410 (2000).

${ }^{79}$ U. Fano and A. Rau, Atomic Collisions and Spectra (Academic, San Diego, California, 1986).

${ }^{80}$ V. Kokoouline and C. H. Greene, Phys. Rev. A 69, 032711 (2004).

${ }^{81}$ F. T. Smith, Phys. Rev. 118, 349 (1960).

${ }^{82}$ A. Hickman, Phys. Rev. A 18, 1339 (1978). 